\title{
ADEQUAÇÃO EMPÍRICA, LINGUAGEM E MUNDO EM THE SCIENTIFIC IMAGE*
}

\author{
Alessio Gava" \\ doi: 10.11144/Javeriana.uph38-76.aelm
}

\section{RESUMO}

Neste ano de 2020, celebra-se o quadragésimo aniversário de The Scientific Image, o seminal livro de Bas van Fraassen. Causa surpresa, depois de tanto tempo, ainda mais considerando o quanto a proposta desse autor foi debatida nestas quatro décadas, a publicação, no número de março da revista Metascience, de mais uma resenha da obra do fundador do empirismo construtivo. Em "Concluding Unscientific Image”, Hans Halvorson defende que nela não se propõe apenas uma defesa de uma perspectiva antirrealista acerca da ciência - e, ao mesmo tempo, uma crítica ao realismo científico -, mas se coloca também em discussão o próprio modo de fazer filosofia que, desde Quine, parecia dominar a filosofia analítica. O presente estudo foca nas alegações de Halvorson acerca daquilo que a afirmação da adequação empírica de uma teoria comportaria - e que segundo ele, van Fraassen teria em mente - e pretende mostrar que talvez não correspondam àquilo que van Fraassen realmente defende em seu livro.

Palavras-chave: adequação empírica; empirismo construtivo; Halvorson; The Scientific Image; van Fraassen

Gostaria de agradecer aos pareceristas anônimos da Revista pelos comentários e sugestões enriquecedores à primeira versão deste trabalho.

- Scuola Italiana Paritaria Enrico Mattei, Casablanca, Marruecos.

Correo electrónico: alessiogava@yahoo.it

Para citar este artículo: Gava, A. (2021). Adequação empírica, linguagem e mundo em The Scientific Image. Universitas Philosophica, 38(76), 223-242. ISSN 0120-5323, ISSN en línea 2346-2426. doi: 10.11144/Javeriana.uph38-76.aelm 


\title{
EMPIRICAL ADEQUACY, LANGUAGE AND WORLD IN THE SCIENTIFIC IMAGE
}

\begin{abstract}
2020 is the year of the fortieth anniversary of Bas van Fraassen's seminal book The Scientific Image. It is quite surprising, after such a long time, and considering how much the author's proposal was debated during the last four decades, to find a new review of it on the March issue of Metascience. In “Concluding Unscientific Image”, Hans Halvorson claims that, in the work of the founder of constructive empiricism, not only is there a defense of an anti-realist perspective on science-and, at the same time, a critique of scientific realism-, but also a revolt against the way of doing philosophy that, since Quine, seemed to be hegemonic in analytical philosophy. The present study focuses on Halvorson's allegations about what maintaining the empirical adequacy of a theory would encompass - and that, according to him, van Fraassen has in mind-and aims at showing that, perhaps, they do not correspond to what van Fraassen actually defends in his book.
\end{abstract}

Keywords: empirical adequacy; constructive empiricism; Halvorson; The Scientific Image; van Fraassen 


\section{Introdução: "Concluding Unscientific Image"}

QUARENTA ANOS JÁ se passaram desde a publicação de The Scientific Image (SI) e nestas quatro décadas rios de tinta foram gastos, literalmente, para tecer comentários sobre vários aspectos do empirismo construtivo, a posição acerca da ciência e de seus objetivos que Bas van Fraassen apresentou no seminal livro de 1980. Foram tantos os estudos que apareceram desde então que alguém poderia compreensivelmente presumir que nada mais haveria a ser acrescentado na análise da vertente que fez ressurgir o pensamento antirrealista na filosofia da ciência em uma época na qual, diversamente, se acreditava que "o caixão do empirismo estivesse devidamente lacrado" (Levi, 1978, p. 737).

Nesse cenário, chega a gerar ainda mais surpresa a aparição de uma nova recensão de SI, no número de março de 2020 da conceituada revista Metascience, justamente especializada em resenhas ("de qualidade elevada", o site da revista faz questão de salientar) de livros de âmbito da história e da filosofia da ciência, bem no ano do quadragésimo aniversário da publicação da obra que projetou o nome de van Fraassen no firmamento dos filósofos contemporâneos mais conhecidos internacionalmente.

Em "Concluding Unscientific Image", Hans Halvorson defende que SI não propõe apenas uma defesa de uma perspectiva antirrealista acerca da ciência, ao mesmo tempo que critica ponto a ponto os pilares sobre os quais o realismo científico está fundamentado, mas coloca também em discussão o próprio modo de fazer filosofia que, desde Quine, parecia dominar aquele horizonte conhecido como "filosofia analítica".

Com efeito, apesar das mudanças, ao longo do século $\mathrm{xx}$, no modo de caracterizar o empreendimento científico, a filosofia analítica parece ter mantido intacta a ideia segundo a qual "a ciência determina o ideal metodológico para a filosofia” (Halvorson, 2020, p. 2) ${ }^{1}$. Comum à ciência e, consequentemente, à filosofia - ou melhor, a alguns filósofos - seria a inclinação a objetificar, ou seja, a necessidade de criar um objeto de estudo. Halvorson propóe uma releitura de $S I$ à luz das críticas de van Fraassen a esse tipo de comprometimento metodológico

1 "science sets the methodological ideal for philosophy." Todas as traduçôes da ressenha de Halvorson (2020) e dos textos não disponíveis em português são nossas. 
dos filósofos analíticos, afirmando que poderiam ser identificadas pelo menos duas tendências presentes no livro: a primeira, mais evidente, seria uma crítica ao realismo científico, conduzida nos moldes de uma investigação própria da filosofia analítica; a segunda, nas entrelinhas, seria uma crítica aos propósitos cientificistas da mesma filosofia analítica.

Segundo Halvorson, aos olhos de van Fraassen, os realistas científicos seriam "culpados" não apenas de serem... realistas científicos; mas, principalmente, de "fazer filosofia da ciência com o intuito de objetificar" (Halvorson 2020, p. 2)2. $\mathrm{O}$ autor dessa nova resenha de $S I$ isola três assunções que seriam típicas de Hilary Putnam e Richard Boyd, escolhidos como representantes exemplares do realismo científico, e tenta mostrar que cada uma delas indicaria uma clara propensão desses realistas - ou dos realistas de modo geral - à objetificação. São elas: holismo, inferência da melhor explicação, continuidade entre filosofia e ciência.

O holismo seria a ideia segundo a qual, na ciência, é a teoria como um todo a ser submetida ao tribunal da experiência, ou seja, não haveria como isolar/ identificar partes dela ("puramente matemáticas" ou "não-empíricas") que eventualmente pudessem ser intepretadas de modo não literal - ou até eliminadas. É notório que van Fraassen rejeita tal concepção e afirma que a máxima virtude que uma teoria pode apresentar, a única genuinamente epistêmica, é a adequação empírica, a saber, a correta descrição daquilo que é observável (para os seres humanos, sem auxílio de instrumentos). Existe, em outras palavras, na visão do fundador do empirismo construtivo, a possibilidade de distinguir a parte observacional de uma teoria científica de sua parte não-observacional - e justamente sobre essa possibilidade, que permitiria manter atitudes diferentes em relação às diversas partes de uma teoria, repousa a vertente antirrealista de van Fraassen.

A tese da inferência da melhor explicação (IBE), como se sabe, prescreve a adoção da hipótese que melhor explica um certo conjunto de dados. Halvorson salienta, porém, corretamente, que a IBE, assim como apresentada pelos realistas científicos, nada mais é do que uma abstração da realidade das coisas, na qual se desconsidera completamente a existência de "pontos de escolha", nos quais os cientistas selecionam os dados a serem considerados ou produzidos ou decidem 
quais hipóteses levar em conta ou construir. Van Fraassen, como também se sabe, critica abertamente a IBE em $S I$.

Quanto à continuidade entre filosofia e ciência, não haveria, em princípio, segundo os realistas, diferenças substanciais entre teses filosóficas e hipóteses científicas. O próprio realismo científico seria uma hipótese empírica a ser confirmada ou rejeitada assim como se faz com as teorias da ciência. Segundo Halvorson, um dos méritos de $S I$ foi ter clareado essa questão e mostrado que pensar as teses filosóficas como hipóteses empíricas - o que representa uma nítida herança quineana - é equivocado. A filosofia não é uma atividade meramente descritiva, mas sempre apresenta um entrelaçamento entre descrição e prescrição.

Halvorson também tem méritos, evidentemente, e o principal deles é ter chamado a atenção para um aspecto da filosofia de van Fraassen sobre o qual, apesar de o mesmo ser evidente e presente não apenas em $S I$, não parece ter havido grandes debates. Em um momento em que a tendência era objectificar e fazer filosofia seguindo um modelo ideal de análise no qual o sujeito não encontra espaço, o autor de origem holandesa fez um movimento não novo na história do pensamento ocidental, mas evidentemente esquecido na filosofia da ciência da segunda metade do século XX, e trouxe de volta, nas discussões sobre a ciência, o protagonismo do agente epistêmico, com seu conjunto de valores e suas escolhas ${ }^{3}$.

3 É precisamente esse movimento que, segundo afirma Halvorson, marca "o início de uma revolta contra a maneira de fazer filosofia de Quine" [ "the beginning of a revolt against Quine's way of doing philosophy”] (2020, p. 1). Com efeito, o autor enxerga nessa atitude objetificante um traço metodológico comum aos filósofos da ciência que antecederam van Fraassen; não apenas Quine, Putnam e Boyd, notoriamente defensores de uma perspectiva realista na análise do empreendimento científico, todavia, mas até mesmo Carnap e os positivistas lógicos; aliás, seria justamente com esses últimos que, na reconstrução de Halvorson, originou-se a ideia segundo a qual a ciência representa o ideal metodológico para a filosofia. Em trabalhos posteriores a SI, van Fraassen critica de modo aberto vários pressupostos metodológicos próprios da filosofia analítica, mas no livro de 1980, apesar de defender uma postura empirista/antirrealista em filosofia da ciência, faz questão de afirmar, ainda na introdução, seu distanciamento não apenas da perspectiva dos realistas científicos, mas também daquela dos positivistas lógicos (van Fraassen, 1980, p. 5). Na obra, van Fraassen reprova de modo enfático o viés linguístico da filosofia neopositivista, à qual atribui a tentativa de transformar (todos) os problemas filosóficos em problemas linguísticos; "em alguns casos - acrescenta o autor de origem holandesa - a orientação linguística [dos positivistas lógicos] produziu efeitos desastrosos, na filosofia da ciência" ["In some cases their linguistic orientation had disastrous effects in philosophy of science"] (p. 4). O artigo de Halvorson nos ajuda a entender que por trás do esforço de van Fraassen para apresentar sua visão acerca da ciência e de seus objetivos 
Isso pode ser percebido não apenas nos tópicos salientados por Halvorson, que selecionou três entre outros que poderiam ter lhe fornecido um terreno fértil para tecer as mesmas considerações, mas também na insistência, de van Fraassen, na dimensão pragmática da explicação científica ou na centralidade por esse último atribuída à observabilidade (humana) na aceitação das teorias produzidas pelos cientistas. "Isso não é antropocentrismo [...], mas simplesmente humanis$m o$, ou seja, o reconhecimento de que não podemos, e não deveríamos tentar, escapar de nós mesmos" ${ }^{\prime \prime}$ escreveu Hasok Chang em 2004 (p. 883). As teorias científicas são produtos humanos; é totalmente legítimo - aliás, é saudável manter uma postura crítica em relação a elas.

O presente estudo, porém, não pretende debater os vários pontos que poderiam ser levantados a partir da análise de Halvorson - são apenas nove páginas, mas poderiam constituir a fonte de diversas discussões - e nem, certamente, limitar-se a ser uma resenha da resenha; o interesse é, diversamente, focar nas alegações de Halvorson acerca daquilo que a afirmação da adequação empírica de uma teoria comportaria e que, segundo ele, van Fraassen teria em mente.

\section{Abordagem semântica e adequação empírica}

NA SEÇÃO DEDICADA AO HOLISMO, Halvorson afirma que, segundo os preceitos da filosofia analítica - que "se vende" como sendo meramente descritiva, mas que na verdade vem com uma série de prescrições bastante rígidas -, se uma certa teoria $T$ é aceita, ela é aceita en bloc. Trata-se de uma versão de holismo que surgiu no âmbito da teoria da confirmação e que, ao realizar uma idealização na qual ignoram-se

como representando uma roptura inclusive em relação à tradição empirista/antirrealista anterior, está uma tentativa de distanciar-se de um certo modo de entender a ciência - e de fazer filosofia da ciência - que perpassa todas as posições anteriores ao empirismo construtivo. Na postura voluntarista/subjetivista do autor de $S I$, estaria assim presente a vontade de compreender a ciência em seus próprios termos, em vez de assumir uma atitude objetificante e tentar reconstruí-la, à la Carnap, por meio de uma linguagem artificial. (Agradeço a um parecerista anônimo da Revista por ter sugerido acrescentar algumas palavras a fim de esclarecer um pouco mais o que Halvorson enxerga no contraste entre a atitude objetificante anterior a van Fraassen e aquela adotada pelo autor de $S I$ ).

4 "There is no anthropocentrism here [...], but only humanism in the form of a recognition that we cannot, and should not try to, get away from ourselves." 
as diferentes atitudes que um agente pode manter no que diz respeito às teorias e às relações dessas com as evidências, afirma que uma teoria é constituída por um bloco único e indivisível. O holismo confirmacional não deixa espaço para a adoção de uma postura crítica em relação às diversas partes de uma teoria, pois essa não necessitaria ser processada antes de ser "ingerida" (Halvorson, 2020, p. 3).

A crítica de van Fraassen ao holismo não é direta, explica Halvorson, mas estaria embutida no novo cenário que o filósofo de origem holandesa supostamente pinta ao dizer que o alvo da confirmação não é uma certa teoria $T$, mas a proposição " $T$ é empiricamente adequada". Nessa mudada perspectiva, agora que não há mais um caminho que leve diretamente de " $T$ é uma teoria de sucesso" a "Deveria-se adotar T", como teria então de comportar-se um "consumidor de ciência" frente ao êxito de uma determinada teoria?

O ponto é que, na opinião do autor de "Concluding Unscientific Image", tampouco existiria um caminho que leve diretamente de " $T$ é uma teoria de sucesso" a "Deveria-se adotar $E(T)$ ", onde $E(T)$ representaria o conjunto de consequências empíricas da teoria 5 .

Com efeito, é notória a escolha, em SI, de uma "abordagem semântica", em detrimento da tradicional "abordagem sintática", que concebia as teorias como conjuntos de axiomas e teoremas enunciados em uma linguagem específica; na perspectiva adotada por van Fraassen, que segue ideias introduzidas por Patrick Suppes nos anos 50 do século passado, afirma-se que a linguagem utilizada para expressar a teoria não é nem básica, nem única e quem ocupa o centro da cena são os modelos dessa (van Fraassen, 1980, p. 44) ${ }^{6}$. Tendo isso em vista, Halvorson

5 Van Fraassen emprega, ao longo de todo $S I$, a locução "conteúdo empírico" (empirical import) para se referir à informação que uma teoria nos dá acerca do observável. Por alguma razão, Halvorson nunca usa essa expressão.

6 Conforme van Fraassen explica em SI, no início do século xx, os filósofos começaram a pensar as teorias científicas segundo um viés linguístico. Para apresentar uma teoria, eles diziam, especifica-se uma linguagem exata, um conjunto de axiomas e um dicionário parcial, que relaciona o dialeto teórico com os fenômenos observáveis (1980, p. 64). Segundo Suppes, diversamente, para apresentar uma teoria define-se diretamente a classe de seus modelos, sem prestar muita atenção ao modo como a mesma é formulada linguisticamente (van Fraassen, 1989, pp. 222-223); com efeito, uma teoria científica pode ser apresentada de maneiras diferentes, quanto à linguagem, mas isso não tem muita importância: o que importa é o conjunto de seus modelos (van Fraassen, 2008, p. 309). 
diz: "Para van Fraassen, não há nenhum $E(T)$ que o consumidor de ciência possa aceitar e van Fraassen não oferece nenhuma receita para traduzir ' $T$ é empiricamente adequada' em um conjunto de sentenças (...) que um leigo deveria aceitar" (2020, p. 3) $)^{7}$; e ainda acrescenta que " $T$ é empiricamente adequada" seria uma sentença meta-linguística, querendo dizer com isso que tal proposição não concerne necessariamente às mesmas coisas que $T$. Não seria, segundo Halvorson, uma teoria acerca do mundo.

$\mathrm{O}$ autor prossegue sugerindo que van Fraassen aponta para um caminho em duas etapas para que um indivíduo possa colher os frutos epistêmicos da atividade científica: (i) a comunidade científica aceita uma certa teoria $T$ (Halvorson fala também em "confirmar" a teoria e não apenas aceitá-la; mas o uso desse verbo poderia ser questionado); (ii) a partir de (i), tomado como um dado, um indivíduo infere " $T$ é empiricamente adequada" (2020, p. 4). É aqui que, na reconstrução de Halvorson, inclusive no contexto caracterizado pela aceitação de uma teoria, van Fraassen (re)introduz o papel do agente epistêmico. Na perspectiva holista/ realista, conforme foi dito, ao aceitar a teoria $T$, o "consumidor de ciência" a aceita en bloc, como verdadeira, sem nenhum processamento. Já segundo a leitura que Halvorson faz de $S I$, quando um indivíduo aprende (ou chega à conclusão) que $T$ é empiricamente adequada, "um desafio lhe é posto: entender como possa ser verdadeiro que $T$ é empiricamente adequada” (Halvorson, 2020, p. 5$)^{8}$.

Dois pontos merecem atenção, na apresentação de Halvorson do pensamento de van Fraassen: a relação entre teoria e linguagem e o fato de " $T$ é empiricamente adequada" não ser, supostamente, uma proposição "acerca do mundo". Eles serão discutidos, de forma separada, nas próximas duas seções.

\section{Teoria, linguagem e adequação empírica}

A INTERPRETAÇÃO DO QUE SERIA UMA TEORIA CIENTÍFICA na perspectiva da abordagem semântica já induziu ao erro autores importantes, desde que van

\footnotetext{
7 "For van Fraassen, there is no E(T) that the consumer of science could accept, and van Fraassen offers no recipe for translating ' $T$ is empirically adequate' into a set of $(. .$.$) sentences that a layperson should accept."$ 
Fraassen introduziu no âmbito da discussão filosófica esse modo de entender os arcabouços conceituais produzidos pelos cientistas. Um deles foi Alan Musgrave, que levantou uma objeção aparentemente eficaz contra o empirismo construtivo em 1985, mas justamente declarando que ignoraria propositalmente a preferência do autor de SI pela abordagem semântica. - Musgrave alegou, entre outras coisas (e com razão), que o próprio van Fraassen fala das teorias científicas como se fossem constituídas por sentenças verdadeiras ou falsas (Musgrave, 1985, p. 198, nota 2) -9 .

Ora, o autor de origem holandesa é enfático na afirmação do caráter (sobretudo) matemático - e não linguístico - das teorias científicas e ao declarar, por exemplo, que o conteúdo empírico delas não pode ser isolado sintaticamente, operando uma distinção entre teoremas em termos de vocabulário (van Fraassen, 1980, p. 54). Ainda assim, admite a (óbvia) necessidade do emprego da linguagem, quando menos no uso das teorias. Se, portanto, toda vez que van Fraassen se utiliza de expressóes como "aquilo que a teoria diz acerca de..." - o que acontece com frequência, tanto em $S I$ quanto em seus trabalhos sucessivos ${ }^{10}-$ devemos intepretar isso cum grano salis e estar cientes de que não se deve tomá-lo

9 Em um artigo que faz parte do volume Images of Science: Constructive Empiricism versus Scientific Realism, que foi publicado cinco anos após $S I$ e contém dez trabalhos selecionados entre os numerosos estudos que tinham o livro de van Fraassen como objeto, Musgrave afirmou haver uma incoerência de fundo insuperável, ao tentar traçar uma distinção entre observáveis e inobserváveis permanecendo fiel aos princípios do empirismo construtivo. $\mathrm{O}$ argumento dele é que se é próprio da ciência desvelar o que é observável e o que não é, conforme van Fraassen defende, a teoria onde isso acontece deve, evidentemente, ser aceita pelo seu usuário. Ora, se o usuário for um empirista construtivo, a aceitação da teoria implica na crença da verdade de suas sentenças acerca de entidades observáveis, tais como, justamente, " $A$ é observável". Com relação aos inobserváveis, por outro lado, o juízo será suspenso e isso aplica-se, segundo Musgrave, também a sentenças acerca deles, tais como " $B$ é inobservável". Um empirista construtivo coerente não poderia assim acreditar na afirmação ou na postulação, feita por uma teoria que ele aceita e considera empiricamente adequada, de que um dado fenômeno não-observável seja, de fato, inobservável para os seres humanos. Ou seja, conclui Musgrave, "o empirismo construtivo requer uma dicotomia que não pode traçar de maneira consistente" ["constructive empiricism requires a dichotomy which it cannot consistently draw"] (Musgrave, 1985, p. 209). O problema, porém, é que o argumento de Musgrave pressupõe uma natureza linguística das teorias cientificas e por essa razão não pode atingir o empirismo construtivo de van Fraassen, que, diversamente, concentra-se nos modelos (geralmente matemáticos) das mesmas.

10 No artigo "The Day of the Dolphins", que faz parte do livro Mistakes of Reason: Essays in Honour of John Woods, por exemplo, escreveu que "o que as ciências falam acerca das partes observáveis do 
literalmente ${ }^{11}$, como se o autor em questão estivesse admitindo uma essência linguística das teorias, isso não significa que a linguagem esteja fora de jogo ou até mesmo que de uma teoria não se possa inferir sentenças.

A objeção de Musgrave mencionada acima foi objeto de outros estudos (por exemplo Muller 2004 e 2005, Dicken \& Lipton 2006), que resultaram na formulação de objeções parecidas, mas que igualmente estão baseadas em uma caracterização informal (sintática) da noção de adequação empírica e também perdem sua força no interior da abordagem semântica. Mas o autor de um desses estudos, F. A. Muller, publicou, em 2008, um artigo em coautoria com o próprio van Fraassen, "How to Talk About Unobservables", no qual se admite que, de fato, adotar a abordagem semântica não isenta do uso da linguagem, com todas as insídias que isso comporta:

$\mathrm{Na}$ abordagem semântica, nos orgulhamos de não ser tão presos à linguagem como [diversamente] se era no período de hegemonia da visão sintática. (...) Contudo, em um contexto caracterizado pela aceitação de certas teorias científicas, essas mesmas teorias irão influenciar ou determinar o uso de palavras e a descrição dos fenômenos em exame (Muller \& van Fraassen 2008, p. 201) ${ }^{12}$.

No artigo se declara, corretamente, que isso já estava de certo modo afirmado na resposta inicial de van Fraassen a Musgrave, também de 1985, na qual é

mundo é verdadeiro, o resto não interessa" ["what the sciences say about the observable parts of the world is true, the rest need not matter”] (van Fraassen, 2005, p. 111).

11 É curioso ter de interpretar - de modo não-literal - as declarações de van Fraassen, sendo que esse defende, em SI, uma construção/intepretação literal da linguagem (sic!) científica (1980, pp. 9-12). Isso acontece inclusive a propósito da questão, crucial para o empirismo construtivo, da observação. Em SI, o autor afirma que dar uma olhada nas luas de Júpiter através de um telescópio constitui "um caso claro de observação" ["a clear case of observation”] (1980, p. 16). A ênfase ("caso claro") parece não deixar dúvidas quanto à opinião de van Fraassen acerca da possibilidade de observar até mesmo quando se usa um telescópio; entretanto, conforme explica Paul Teller, comentando justamente a afirmação de van Fraassen, "aquilo que fazemos com um telescópio não conta como observação [...] no sentido relevante" ["what we do with a telescope does not itself count as observing [...] in the relevant sense"] (Teller, 2001, p. 126), o que significaria que o autor de SI nunca quis realmente dizer que alguém pode realizar uma observação por meio de um telescópio.

12 "In the semantic approach, we pride ourselves on not being so language-bound as one was during the hegemony of the syntactic view. [...] Yet in a context characterized by acceptance of given scientific theories, those theories will shape or constrain the use of words and the description of the phenomena under study." 
admitido que de uma teoria pode derivar - ou ser extraída - uma sentença (van Fraassen 1985, p. 256). Mas sobre a inescapabilidade do uso da linguagem, van Fraassen tinha se manifestado inclusive em SI: "O comprometimento epistêmico para com o conteúdo empírico da teoria [...] (a sua adequação empírica) pode ser expressado utilizando a linguagem da ciência - e, deveras, em nenhum outro modo" (1980, p. 81) ${ }^{13}$. Ainda assim, é em "How to Talk About Unobservables" que isso é afirmado de modo a não deixar dúvidas:

Se questionados acerca daquilo que uma teoria diz, temos de responder usando a mesma linguagem na qual a pergunta foi formulada; ou, talvez, utilizando uma extensão adequada daquela linguagem. E se nos perguntam no que acredita quem aceita uma certa teoria, [ou seja,] alguém que acredita que a teoria é empiricamente adequada, também temos de responder à pergunta na mesma linguagem na qual ela foi formulada. Isso é válido mesmo que aqui as teorias científicas não estejam sendo concebidas como identificáveis com - ou através de - sua formulação em uma linguagem específica (Muller \& van Fraassen, 2008, pp. 203-204) ${ }^{14}$.

Isso significa que então existe uma receita para traduzir " $T$ é empiricamente adequada” em um conjunto de sentenças que um leigo deveria aceitar? É certo que, diversamente de como pensavam os positivistas lógicos, não podemos identificar o conteúdo empírico de uma teoria $T$ com uma classe de sentenças $T / E$, o que envolveria a impossível tarefa de identificar um subvocabulário observacional $E$, mas ainda assim podemos certamente pensar em um conjunto de sentenças que decorrem da teoria ou de sua aceitação. Halvorson afirma que, no âmbito do empirismo construtivo, " $T$ é empiricamente adequada" seria uma proposição meta-linguística, a saber, uma sentença que não poderia ser traduzida em um conjunto de outras sentenças. Mesmo que esse fosse o caso, o próprio van

13 "The epistemic commitment to the empirical import of the theory (...) (its empirical adequacy) can be stated using the language of science - and indeed, in no other way."

14 "If asked what a theory says, we must answer in the language in which the question is asked, or perhaps in a suitable extension of that language. And if we are asked what an acceptor of a given theory believes, someone who believes the theory to be empirically adequate, we must also answer that question in the language in which it is asked. This point stands although scientific theories are here not conceived as identified with or through their formulation in any specific language." 
Fraassen, no artigo escrito em coautoria com Muller, admite que no contexto caracterizado pela aceitação de uma teoria é mister utilizar uma linguagem (nãomatemática); mais ainda, que de uma teoria resultam (ou podem resultar) sentenças. Não parece correto, portanto, à luz do exposto, afirmar que "van Fraassen não oferece nenhuma receita para traduzir ' $T$ é empiricamente adequada' em um conjunto de sentenças [...] que um leigo deveria aceitar" (Halvorson, 2020, p. 3$)^{15}$. Ainda que o autor de origem holandesa defenda a impossibilidade de se isolar sintaticamente, por meio de um operação linguística, o conteúdo empírico de uma teoria, há certamente sentenças decorrentes de " $T$ é empiricamente adequada" que um leigo pode aceitar.

Concluo a presente seção com três observações: (i) a proposição " $T$ é empiricamente adequada" e a teoria $T$ são evidentementes duas entidades distintas, e até de natureza diferente: a primeira é um objeto linguístico, a segunda um objeto (de caráter eminentemente) matemático - conforme defende van Fraassen. A impossibilidade de se isolar sintaticamente o conteúdo empírico de $T$ não necessariamente acarreta uma impossibilidade de traduzir " $T$ é empiricamente adequada" em um conjunto de sentenças - como diversamente Halvorson deixa entender; ainda mais considerando que é ela mesma uma sentença. (ii) Ao falar de "um conjunto de sentenças que um leigo deveria aceitar", Halvorson parece desconsiderar o liberalismo epistêmico de van Fraassen, que se auto-define voluntarista e adota um modelo de racionalidade permissivo (típico da tradição anglo-saxã) e não normativo (característico da tradição continental). Segundo a epistemologia voluntarista, como bem explica Paul Dicken (2010, p. 23), a racionalidade deve ser considerada mais uma questão de permissão do que de obrigação e é perfeitamente legítimo, nessa perspectiva, acreditar em tudo aquilo que não somos racionalmente forçados a não acreditar. Em outras palavras, van Fraassen nunca defenderia que alguém deveria adotar $T / E$, mesmo que admitisse a possibilidade de se isolar sintaticamente o conteúdo empírico de uma teoria. (iii) Conceder que van Fraassen reconhece a parcial viabilidade de uma distinção linguística entre a parte observacional de uma teoria e aquela candidata a representar aspectos inobserváveis do mundo, ainda que não seja possível isolar sintaticamente o conteúdo

15 "van Fraassen offers no recipe for translating ' $\mathrm{T}$ is empirically adequate' into a set of [...] sentences that a layperson should accept." 
empírico, não abalaria o ponto principal de Halvorson. Pelo contrário, tornaria a crítica implícita do autor de $S I$ ao holismo mais robusta do que "colocar $T$ em um contexto opaco" (Halvorson, 2020, p. 4$)^{16}$.

\section{4. " $T$ é empiricamente adequada" e o mundo}

Conforme foi ilustrado anteriormente, Halvorson defende que $S I$ promoveu uma radical mudança de cena, no contexto caracterizado pela aceitação de uma teoria científica: o alvo da confirmação não seria mais a teoria $T$, como era para os realistas científicos, mas a proposição " $T$ é empiricamente adequada" - doravante $P(T)^{17}$. Mas tal proposição apresentaria uma natureza meta-linguística, apesar de ser, evidentemente, um objeto linguístico. "Em outras palavras - explica Halvorson -, $[P(T)]$ não é necessariamente acerca das mesmas coisas que $T$. Não se trata de uma teoria acerca do mundo" (Halvorson, 2020, p. 3$)^{18}$.

Ora, uma vez esclarecido que nenhuma teoria científica é "acerca do mundo", mas sempre sobre um aspecto bem delimitado do mesmo (um dominio), é evidente que a proposição em questão tem como alvo principal a teoria $T$; não sendo tal teoria acerca de si mesma, " $T$ é empiricamente adequada" e $T$ têm de fato domínios diferentes. Não seria $P(T)$ acerca de um aspecto do mundo também? Mas, principalmente, é correto dizer que o alvo da confirmação não é mais a teoria $T$ (e sim alguma outra coisa)?

Vamos ver o que Halvorson diz a respeito de $P(T)$. Conforme relatado na seção dois, segundo esse autor, van Fraassen nos mostraria a existência de um caminho em duas etapas para se chegar à proposição em questão: (i) a comunidade científica confirma e aceita a teoria $T$; (ii) um indivíduo toma "a comunidade

16 "placing T into an opaque context."

17 Não está claro por que um realista científico não poderia replicar que se o alvo da confirmação não é mais a teoria $T$, então o é a proposição " $T$ é verdadeira" - ou " $T$ nos proporciona um relato literalmente verdadeiro de como o mundo é”, etc.

18 "In other words, it is not necessarily about the same thing that $\mathrm{T}$ is about. It is not itself a theory about the world." 
científica confirmou e aceitou $T$ " como um dado empírico e disso infere que " $T$ é empiricamente adequada" (Halvorson, 2020, p. 4).

O primeiro estágio é emblemático. Após ter atribuído a van Fraassen a paternidade de uma mudança de cena radical, no âmbito da aceitação de uma teoria científica, segundo a qual o alvo da confirmação não seria mais uma teoria mas uma proposição, Halvorson escreve que, de acordo com o autor holandês, para se chegar a $P(T)$, o primeiro passo é: "a comunidade científica confirma e aceita a teoria $T^{\text {’ }}$ (Halvorson, 2020, p. 4, ênfase nossa). ${ }^{19}$ Alguém aqui poderia entrever uma contradição entre a afirmação de que o alvo da confirmação não é a teoria e aquela segundo a qual a comunidade científica confirma justamente a teoria. Mas vamos admitir que o alvo da confirmação seja "a teoria sobre a teoria" ${ }^{20}$, ou seja, $P(T)$, e não a própria $T$. Por que haveria de ter duas etapas, conforme Halvorson atribui a van Fraassen?

Ao apresentar o empirismo construtivo, em $S I$, o autor de origem holandesa escreveu: "a ciência tem por objetivo nos fornecer teorias que sejam empiricamente adequadas; e a aceitação de uma teoria envolve, como crença, apenas a de que essa é empiricamente adequada" (van Fraassen 1980, p. 12, ênfase no original) ${ }^{21}$. Esse seria, continua van Fraassen, o enunciado da vertente antirrealista que defende. Note-se que, nesse enunciado, está afirmado de modo inequívoco que a aceitação de uma teoria envolve a crença de que ela é empiricamente adequada. Isso significa que se a comunidade científica confirma e aceita $T$, seus integrantes automaticamente acreditam que " $T$ é empiricamente adequada" - e alguém poderia até arriscar-se a afirmar que a aceitação da teoria provavelmente decorre da crença, que a comunidade científica formou, de que a teoria em exame é

19 "The scientific community confirms and accepts a theory T."

20 A expressão "teoria sobre a teoria" não deve ser tomada literalmente, ou pelo menos van Fraassen discordaria dela, pois $P(T)$ é uma proposição, portanto um objeto linguístico, e o autor do $S I$ justamente recusa a ideia de que teorias sejam objetos linguísticos. Mas isso torna ainda mais complicada a reconstrução de Halvorson, o qual diz que segundo van Fraassen o alvo da confirmação não seria mais a teoria $T$, como diversamente seria se ele fosse um realista científico, mas a proposição " $T$ é empiricamente adequada". Será que van Fraassen, em $S I$, está realmente preocupado com a confirmação de sentenças e não com a aceitação de teorias científicas?

21 "Science aims to give us theories which are empirically adequate; and acceptance of a theory involves as belief only that it is empirically adequate." 
empiricamente adequada; ou seja, a aceitação de $P(T)$ antecederia a aceitação de $T$, e não vice-versa.

Em outras palavras, quem julga a adequação de $P(T)$ - e portanto aceita a proposição - é a própria comunidade científica. Não parece apropriada a reconstrução em duas etapas de Halvorson, como se os cientistas fossem "o braço", com a tarefa de confirmar e aceitar $T$, e os leigos (os filósofos?) "a mente", que a partir do resultado do trabalho dos cientistas inferem que " $T$ é empiricamente adequada". Mas o que mais interessa aqui é que não parece correto atribuir a paternidade disso a van Fraassen. Uma leitura das seções 1.2 e 1.3 de $S I$ não deixa muitas dúvidas a esse respeito. Por outro lado, quem melhor de um cientista para julgar se uma certa afirmação acerca da adequação empírica de uma teoria é ela mesma empiricamente adequada (ou até verdadeira, nesse caso)? Assim como uma pessoa de bom senso se dirigiria a um médico especialista, e não a um político ou a um pastor, para informar-se acerca da pericolosidade de um determinado vírus ou da eficácia de um certo medicamento, do mesmo modo um leigo (ou um filósofo) consulta um especialista - um cientista, nesse caso - para saber se uma teoria científica é empiricamente adequada ou não.

Seria assim, então, que um filósofo chega a "apropriar-se" de " $T$ é empiricamente adequada"? Ou isso acontece do modo descrito por Halvorson, ou seja, o não-cientista infere isso a partir da informação de que a comunidade científica confirmou e aceitou T?22 Segundo o autor de "Concluding Unscientific Image", entender como possa ser verdadeiro que $T$ é empiricamente adequada representa um desafio para quem aprende/fica sabendo que esse é o caso. Ora, provavelmente não há um caminho unívoco e cada leigo terá seu modo de interiorizar o conhecimento representado por $P(T)$; mas a melhor resposta a Halvorson, provavelmente, é: isso não importa. SI é um livro de filosofia da ciência, não de meta-filosofia da ciência. Van Fraassen não está preocupado em saber como um filósofo ou qualquer outro leigo se põe, frente ao trabalho e aos resultados dos cientistas. Ele está preocupado, é em "dar conta" (make sense) da ciência (Buekens \& Muller, 2012, p. 94), não dos "consumidores de ciência" ou dos espectadores do esforço dos cientistas.

22 E um leigo (ou um filósofo) simpático ao realismo científico, não poderia inferir que " $T$ é verdadeira en bloc", a partir da mesma informação? 
Vale a pena ainda, de qualquer modo, gastar algumas palavras sobre a afirmação segundo a qual " $T$ é empiricamente adequada" não seria uma teoria acerca do mundo. É verdade que aos olhos de van Fraassen ela provavelmente não é uma teoria, mas isso não significa que não trate de algum aspecto da realidade ao nosso redor ${ }^{23}$. Se $P(T)$ é gerada pelos cientistas, isso significa que a mesma diz respeito à relação da teoria $T$ com o mundo e que se chegou a ela ao observar tanto a teoria quanto algum aspecto da realidade e constatar que subsiste um isomorfismo entre certas partes dos modelos que fazem parte de $T$ (as subestruturas empiricas), ou seja, a sua parte observacional, e as "aparências" (as estruturas que podem ser descritas em relatos experimentais e de medição), que correspondem aos "fenômenos observáveis" (van Fraassen, 1980, p. 64). Nesse caso, resultaria difícil negar que " $T$ é empiricamente adequada" é acerca (de algum aspecto) do mundo, seja ela uma teoria ou apenas uma proposição.

Se, diversamente, de acordo com a reconstrução de Halvorson, $P(T)$ fosse gerada por um filósofo (ou qualquer outro leigo), ela provavelmente seria o resultado de uma série de observações de um determinado aspecto da realidade (a comunidade científica e o comportamento de seus integrantes). O fato de, inclusive nesse caso, ser difícil negar que se trataria de qualquer modo de uma afirmação acerca (de alguma feição) do mundo, é reforçado pela seguinte consideração: se for verdade que o processo de geração de $P(T)$ é aquele descrito por Halvorson - um indivíduo toma "a comunidade científica confirmou e aceitou $T$ " (vamos chamar essa proposição de $A(T)$ ) como um dado empírico e disso infere que " $T$ é empiricamente adequada” -, isso significa também que $P(T) \rightarrow A(T)$. Ora, o consequente dessa condicional é inegavelmente uma descrição de um estado de coisas no mundo (o que significaria, diversamente, "a comunidade científica confirmou e aceitou $T$ ”?); logo, a própria $P(T)$ é, entre outras coisas, uma descrição de um estado de coisas no mundo. Em outras palavras, " $T$ é empiricamente adequada" é uma proposição acerca do mundo - e note-se que acabamos de ver que, contra Halvorson, dela decorre pelo menos uma sentença, que evidentemente o leigo pode aceitar.

23 Alguém poderia replicar que se $P(T)$ é uma proposição acerca do mundo, então Halvorson está correto em dizer que a mesma não é uma teoria acerca do mundo; mas não parece mesmo ser isso aquilo que o autor de "Concluding Unscientific Image" tinha em mente, ao fazer tal afirmação. 
Em suma, é verdade que $T$ e $P(T)$ apresentam domínios diferentes, mas a afirmação segundo a qual " $T$ é empiricamente adequada” não seria (uma teoria? Por que não?) acerca do mundo, não parece correta. ${ }^{24}$ Pace Halvorson.

\section{Conclusão}

\section{À surpresa de Ver publicada uma Resenha de The SCIENTIFIC IMage no ano em que a edição do seminal livro de van Fraassen completa quarenta anos} se acrescenta a grata constatação de que a obra do autor de origem holandesa ainda "tem fôlego" para nos ajudar a entender um pouco melhor a ciência, seus mecanismos e seus propósitos. "Concluding Unscientific Image" tem o mérito de, em poucas páginas, apontar para um aspecto importante da filosofia de van Fraassen, presente em $S I$; a saber, o fato de ter trazido de volta, nas discussões sobre a ciência, o protagonismo do agente epistêmico, com seu conjunto de valores e suas escolhas - o que parecia ter saído de cena na filosofia analítica da segunda metade do século xx.

24 Na presente seção, entrei no mérito das afirmações de Halvorson e, rebatendo diretamente as alegações do autor, tentei mostrar que, quanto à natureza da proposição " $T$ é empiricamente adequada" e à relação dessa com o mundo, provavelmente as coisas não estão do modo descrito em "Concluding Unscientific Image". Mas talvez não fosse necessário. Van Fraassen é um dos filósofos contemporâneos mais conhecidos internacionalmente, notoriamente defensor de uma stance empirista/ antirrealista na análise filosófica do empreendimento científico - da mais proeminente da atualidade, dizem alguns. No prefácio do livro The Empirical Stance, o fundador do empirismo construtivo escreveu que, em $S I$, tentou definir "o que seria a ciência empírica, segundo um empirista, nos dias atuais" ["what empirical science is according to an empiricist today"] (2002, p. xiii). Seria no mínimo bizarro se, em um livro dedicado a apresentar uma proposta de perspectiva empirista contemporânea, o aspirante empirista van Fraassen (assim ele costuma apresentar-se em público) defendesse que o alvo da confirmação não é uma certa teoria $T$, mas sim uma proposição "meta-linguística" a respeito da mesma, que porém não seria 'acerca do mundo.' Se a afirmação de que certa teoria é empiricamente adequada não consistisse em uma proposição sobre o mundo, isso significaria que a máxima virtude que uma teoria pode apresentar, a única que van Fraassen julga ser genuinamente epistêmica, a saber, a correta descrição daquilo que é observável, que o autor de origem holandesa chama de adequação empirica, poderia ser decretada de modo não-empírico. Parece bastante complicado atribuir a van Fraassen uma posição como essa. (Agradeço a um parecerista anônimo da Revista por ter me convidado a expor a importância, para a concepção de van Fraassen, de que a afirmação de que certa teoria é empiricamente adequada consiste numa afirmação sobre o mundo, em contraste ao que Halvorson insiste em sua resenha). 
Além disso, conforme foi afirmado neste trabalho, a análise de Halvorson poderia ser tomada como ponto de partida para mais de uma reflexão sobre aspectos do empirismo construtivo ou sobre a ciência e seu modus operandi. No presente estudo, dois ângulos da apresentação de Halvorson do pensamento de van Fraassen foram objeto de exame: a relação entre teoria e linguagem e o fato de " $T$ é empiricamente adequada" não ser, supostamente, uma proposição "acerca do mundo".

Foi mostrado que, apesar de o autor de origem holandesa ter anunciado explicitamente e reafirmado várias vezes, em $S I$, sua preferência por uma "abordagem semântica” às teorias, em detrimento da tradicional "abordagem sintática” da "visão recebida", de modo que a atenção seja dirigida para os modelos desses arcabouços conceituais e não para conjuntos de axiomas e teoremas redigidos em uma linguagem específica, ainda assim o recurso à linguagem é ineludível. Halvorson afirma que da aceitação de uma teoria como sendo empiricamente adequada não decorre um conjunto de sentenças nas quais acreditar - e atribui essa visão a van Fraassen. Mas na verdade, o próprio fundador do empirismo construtivo, em um artigo de 2008 escrito em coautoria com o também holandês Muller, admite que, justamente no contexto caracterizado pela aceitação de uma teoria - mas não só, em vários outros "usos" da ciência e de "seus produtos" também -, é mister utilizar uma linguagem (não-matemática); mais ainda, que de uma teoria resultam (ou podem resultar) sentenças, nas quais, evidentemente, um "consumidor de ciência" pode acreditar.

A esse aspecto está ligado o segundo tema que foi objeto de atenção no presente estudo: o fato de " $T$ é empiricamente adequada" não ser, no dizer de Halvorson, "uma teoria acerca do mundo". Ora, provavelmente van Fraassen não aceitaria classificar uma sentença como sendo uma teoria, mas sem entrar no mérito dessa questão, foi mostrado que tal proposição é acerca do mundo, tanto no caso em que ela seja "produzida" pela comunidade científica ao aceitar a teoria $T$, quanto no caso em que, conforme Halvorson parece defender - mas será que a mesma visão poderia ser atribuída a van Fraassen? -, a paternidade dela deva ser atribuída a algum leigo (um filósofo, talvez), o qual chegaria a enunciá-la como resultado da constatação de que $T$ foi confirmada e aceita pelos cientistas.

Enfim, a reconstrução do pensamento de van Fraassen operada por Halvorson parece apresentar aspectos questionáveis, mas esse último conseguiu mostrar ao 
mundo que o empirismo construtivo ainda é alive and kicking e, principamente, que Scientific Image é, como diria Nanni Moretti, uno splendido quarantenne.

Salve Halvorson! Salve van Fraassen!

Referências

Buekens, F. \& Muller, F. A. (2012). Intentionality Versus Constructive Empiricism. Erkenntnis, 76 (1), 91-100. doi: 10.1007/s10670-011-9348-1

Chang, H. (2004). A Case for Old-fashioned Observability, and a Reconstructed Constructive Empiricism. In: Proceedings Philosophy of Science Association $19^{\text {th }}$ Biennial Meeting - PSA 2004: PSA 2004 Contributed Papers, Austin, 876-887. https://doi.org/10.1086/508116

Dicken, P. (2010). Constructive Empiricism. Epistemology and the Philosophy of Science. Palgrave Macmillan.

Dicken, P. \& Lipton, P. (2006). What Can Bas Believe? Musgrave and Van Fraassen on Observability. Analysis, 66 (3), 226-233. https://doi.org/10.1093/ analys/66.3.226

Fraassen, B. C. van (1980). The Scientific Image. Oxford: Clarendon Press.

Fraassen, B. C. van (1985). Empiricism in the Philosophy of Science. In: P. Churchland \& C. Hooker (Eds.), Images of Science. Essays on Realism and Empiricism, with a Reply form Bas C. van Fraassen (pp. 245-308). Chicago: The University of Chicago Press.

Fraassen, B. C. van (1989). Laws and Symmetry. Oxford: Clarendon Press.

Fraassen, B. C. van (2005). The Day of the Dolphins. Puzzling over Epistemic Partnership. In: A. Irvine \& K. Peacock (Eds.), Mistakes of Reason: Essays in Honour of John Woods (pp. 111-133). Toronto: University of Toronto Press.

Fraassen, B. C. van (2008). Scientific Representation: Paradoxes of Perspective. Oxford: Clarendon Press.

Halvorson, H. (2020). Concluding Unscientific Image. Metascience. https:// doi.org/10.1007/s11016-020-00506-2

Levi, I. (1978). Confirmational Conditionalization. The Journal of Philosophy, 75 (12), 730-737. 
Muller, F. A. (2004). Can a Constructive Empiricist Adopt the Concept of Observability? Philosophy of Science, 71 (1), 637-654. https://doi. org/10.1086/381414

Muller, F. A. (2005). The Deep Black Sea: Observability and Modality Afloat. British Journal for the Philosophy of Science, 56 (1), 61-99. https://doi. org/10.1093/phisci/axi103

Muller, F. A.; Fraassen, B. C. van. (2008). How to Talk About Unobservables. Analysis, 68 (3), 197-205. https://doi.org/10.1093/analys/68.3.197

Musgrave, A. (1985). Realism Versus Constructive Empiricism. In: P. Churchland \& C. Hooker (Eds.), Images of Science. Essays on Realism and Empiricism, with a Reply form Bas C. van Fraassen (pp. 197-221). Chicago: The University of Chicago Press.

Teller, P. (2001). Whither Constructive Empiricism? Philosophical Studies, 106 (1-2), 123-150. https://doi.org/10.1023/A:1013170506726 